\title{
Genetic characterization of H1N2 influenza a virus isolated from sick pigs in Southern China in 2010
}

\author{
Wei Li Kong ${ }^{\dagger}$, Liang Zong Huang ${ }^{\dagger}$, Hai Tao Qi, Nan Cao, Liang Quan Zhang, Heng Wang, Shang Song Guan, \\ Wen Bao Qi, Pei Rong Jiao, Ming Liao and Gui Hong Zhang*
}

\begin{abstract}
In China H3N2 and H1N1 swine influenza viruses have been circulating for many years. In January 2010, before swine were infected with foot and mouth disease in Guangdong, some pigs have shown flu-like symptoms: cough, sneeze, runny nose and fever. We collected the nasopharyngeal swab of all sick pigs as much as possible. One subtype H1N2 influenza viruses were isolated from the pig population. The complete genome of one isolate, designated A/swine/Guangdong/1/2010(H1N2), was sequenced and compared with sequences available in GenBank. The nucleotide sequences of all eight viral RNA segments were determined, and then phylogenetic analysis was performed using the neighbor-joining method. HA, NP, M and NS were shown to be closely to swine origin. PB2 and PA were close to avian origin, but NA and PB1were close to human origin. It is a result of a multiple reassortment event. In conclusion, our finding provides further evidence about the interspecies transmission of avian influenza viruses to pigs and emphasizes the importance of reinforcing swine influenza virus (SIV) surveillance, especially before the emergence of highly pathogenic FMDs in pigs in Guangdong.
\end{abstract}

\section{Findings}

Influenza viruses are members of family Orthomyxoviridae and have segmented, Negative-sense RNA genomes. Swine influenza virus (SIV) belongs to Influenza A Viruses. SIV causes respiratory diseases in pigs and has been disseminated all over the world [1]. At present, there were three main influenza viruses circulating in pigs in the world including $\mathrm{H} 1 \mathrm{~N} 1, \mathrm{H} 1 \mathrm{~N} 2$ and $\mathrm{H} 3 \mathrm{~N} 2$. In addition some other unusual subtypes of swine influenza were also reported includingH1N7, H3N1, H4N6, H5N1, H5N2, H6N6 and H9N2 [2-7].

The first SIV H1N2 was reported in Japan from 1978 to $1992[8,9]$. From then on, H1N2 was show up in different pigs of different countries, including France from 1987 to 1988 [10], and in the United Kingdom in 1994 [11], the United States in 1999 [12], Germany in 2000 [13], Korea in 2003 and thereafter [14]. Recently it first shows up in Swedish herd [15]. During an influenza virus surveillance programme in Guangdong pigs, we isolated an $\mathrm{H} 1 \mathrm{~N} 2$ virus from clinically ill pigs, which was genetically characterized as a result of reassortment events between a

\footnotetext{
* Correspondence: guihongzh@scau.edu.cn

† Contributed equally

College of Veterinary Medicine, South China Agricultural University,
} Guangzhou, China human H3N2 strain, Classical SIV strain and North America avian-like SIV lineage strain.

In January of 2010, some pigs have a severe outbreak of influenza-like disease occurred in an intensive pig farm of Guangdong province. Many pigs have similar clinical symptoms: cough, sneeze, runny nose. These clinical symptoms last for 3-8 days then some pigs have sick of foot and mouth disease (FMD). Because Swine influenza (SI) was immunosuppressive disease which frequently predisposesed to highly fatal secondary infections. Maybe the SI lowers pig's immunity to common illnesses, some pigs will get FMD. From now on, the FMD caused rampant epidemic diseases in pig population of Guangdong [16].

Initial isolations of the viruses were performed in 10day-old specific pathogen free (SPF) embryonated chicken eggs through the allantoic route, incubated at $35^{\circ} \mathrm{C}$ for $72 \mathrm{~h}$. Embryonic death was monitored every $12 \mathrm{~h}$, and then allantoic fluid were harvested under aseptic conditions and stored at $-70^{\circ} \mathrm{C}$ for reserved. Subtype identification were conducted through RT-PCR and through standard hemagglutination inhibition and neuraminidase inhibition assays. One influenza virus was isolated and named: A/swine/Guangdong/1/2010(H1N2).

The virus RNA was extracted from allantoic fluid by using TRIzol reagents (Invitrogen). RT-PCR was
C Biomed Central

() 2011 Kong et al; licensee BioMed Central Ltd. This is an Open Access article distributed under the terms of the Creative Commons Attribution License (http://creativecommons.org/licenses/by/2.0), which permits unrestricted use, distribution, and reproduction in any medium, provided the original work is properly cited. 
performed as a one-step reaction with the TAKARA OneStep RT-PCR Kit, according to manufacturer's protocol. The primer of reverse transcription used 12 bp (5-AGC AAA AGC AGG-3). cDNAs were synthesized at $37^{\circ} \mathrm{C}$ for $1 \mathrm{~h}$ using M-MLV reverse-transcription system (Promega). Full-length PCR amplification of eight RNA segments was performed with a set of primer. The genome of this H1N2 SIV was sequenced fully as described previously, with the GenBank accession numbers HQ85339 to HQ853346.

Phylogenetic analysis of A/swine/Guangdong/1/2010 (H1N2) was carried out by analyzing the data obtained here with those of other sequences of influenza viruses from GenBank database. A neighbor-joining nucleic acid tree was constructed in MEGA 4.0 using the Kimura 2parameter model with 1, 000 bootstrap replicates. Clustal W of Lasergene was used for multiple alignments. In this study, the nucleotide sequences used for the phylogenetic analysis are as follows: PB2 (nt 100-2307), PB1 (nt 468-2297), PA (nt 479-2150), HA (nt 65-1689), NP (nt 45-1563), NA (nt 35-1422), M (nt 25-996), NS (nt 41-852). Table 1 lists the reference viruses with the highest level of sequence identity to A/swine/Guangdong/1/2010 for each gene segment.

The HA deduced amino acid sequences of the A/ swine/Guangdong/1/2010 was analyzed in this study. There were eight potential glycosylation sites in HA, including six in HA1 and two in HA2. Its cleavage site is (PSIQSRGLFGAI), which is not same with the HPAI (RXR/KRGLF) of the 1918 influenza virus which have strong pathogenic effect on the human (Figure 1).

Phylogenetic analysis revealed that the HA gene of A/swine/Guangdong/1/2010 is of classical swine lineage resides in the same clade with pandemic (H1N1) 2009A/ California/04/2009, along with A/swine/Beijing/47/1991 (H1N1) and A/Swine/Indiana/9K035/99(H1N2) (Figure 2). Sequence homology with A/swine/Beijing/47/1991(H1N1) and A/swine/Hong Kong/273/1994(H1N1) was respectively found to be $94.6 \%$ and $93.9 \%$. It still has a high homology with A/Swine/Indiana/9K035/99(H1N2) with $92.1 \%$, which is the first reported triple reassortment swine influenza virus H1N2 in United States [12]. A/swine/Cloppenburg/IDT4777/2005(H1N2) is a novel SIV H1N2 isolated from Germany, whose HA gene originated from a human epidemic strain, is clearly distinct in genetic origin compared with those classical SIVs. Therefore, it is obviously that the HA gene of A/swine/Guangdong/1/2010 is a descendent of classical SIV and originated from the HA gene of neither avian origin nor human origin.

The phylogeny of the NA genes (Figure 3) also demonstrated that $\mathrm{A} /$ swine/Guangdong/1/2010 is genetically related to A/New York/568/1996(H3N2) and that the NA genes of triple reassortment H3N2(TRH3N2) North American human [A/Ontario/RV1273/ 2005] and swine [A/swine/Ontario/33853/2005] and avian [A/mallard/South Dakota/Sg-00128/2007] influenza virus have established themselves as a single clade $[17,18]$. This clade shares a common ancestor with the human H3N2 viruses isolated during the 1990s in New York [A/New York/568/1996(H3N2)]. Comparison of partial sequences of the NA genes between TR-H3N2 and A/Turkey/MO/24093/99(H1N2) [19] showed high value of identities (94.0\%-97.2\% and 97.4\%, respectively), which suggested close relationship between these viruses. Sequence homology (bp) with A/New York/568/ 1996 was identified as $96.5 \%$. When compared with European H3N2 SIV and Avian-like SIV, a low degree of similarity is respectively observed as $85.3 \%-87.8 \%$ and $81.8 \%-84.9 \%$.

Phylogenetic trees of the nucleotide sequences of NP, $\mathrm{M}$ and NS were involved in the classical SIV lineage. Different subtype triple reassortment influenza viruses still stand with them in the same clade. PB2 and PA was likely originated from North America avian-like SIV lineage. PB1 was close to human H3N2 lineage as the NA gene. (By way of example, the phylograms for the PB1, PB2, $\mathrm{PA}, \mathrm{NP}, \mathrm{M}$ and NS genes of the viruses featured in the present study are available in the additional files 1, 2, 3, 4,5 and 6 ).

The PB1-F2 protein of influenza A virus encoded by an alternative reading frame in the $\mathrm{PB} 1$ polymerase

Table 1 Sequence homology of each gene from A/swine/Guangdong/1/2010 (H1N2) and reference virus sequences available in GenBank

\begin{tabular}{lllll}
\hline Gene & Region & Virus with the highest degree of homology & Nucleotide sequence Identity (\%) & Influenza virus lineage \\
\hline HA & $65-1689$ & A/swine/Beijing/47/1991(H1N1)[U46783] & 94.6 & Swine \\
NA & $35-1422$ & A/Turkey/MO/24093/99(H1N2)[AY038015] & 97.4 & Human \\
PB2 & $100-2307$ & A/swine/HongKong/NS623/2002(H1N2)[GQ229369] & 98.1 & Avian \\
PB1 & $468-2297$ & A/turkey/Ontario/31232/2005(H3N2)[DQ469996] & 99.8 & Human \\
PA & $479-2150$ & A/swine/HongKong/NS623/2002(H1N2)[GQ229368] & 97.5 & Avian \\
NP & $45-1563$ & A/swine/Hong Kong/915/2004(H1N2) [GQ229270] & 98.0 & Swine \\
M & $25-996$ & A/swine/HongKong/NS623/2002(H1N2)[GQ229367] & 98.9 & Swine \\
NS & $41-852$ & A/swine/Hong Kong/1110/2006(H1N2) [GQ229371] & 97.6 & Swine \\
\hline
\end{tabular}




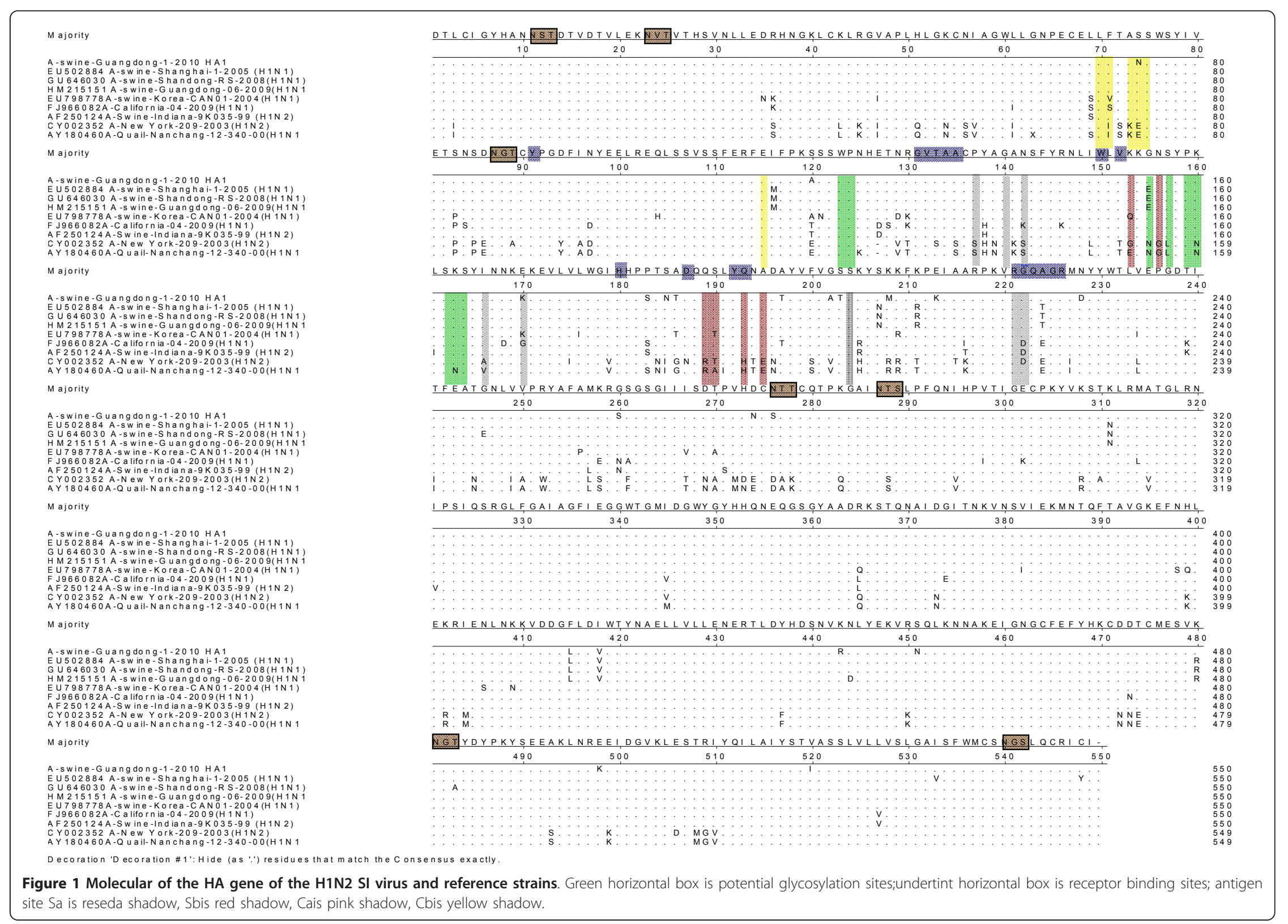




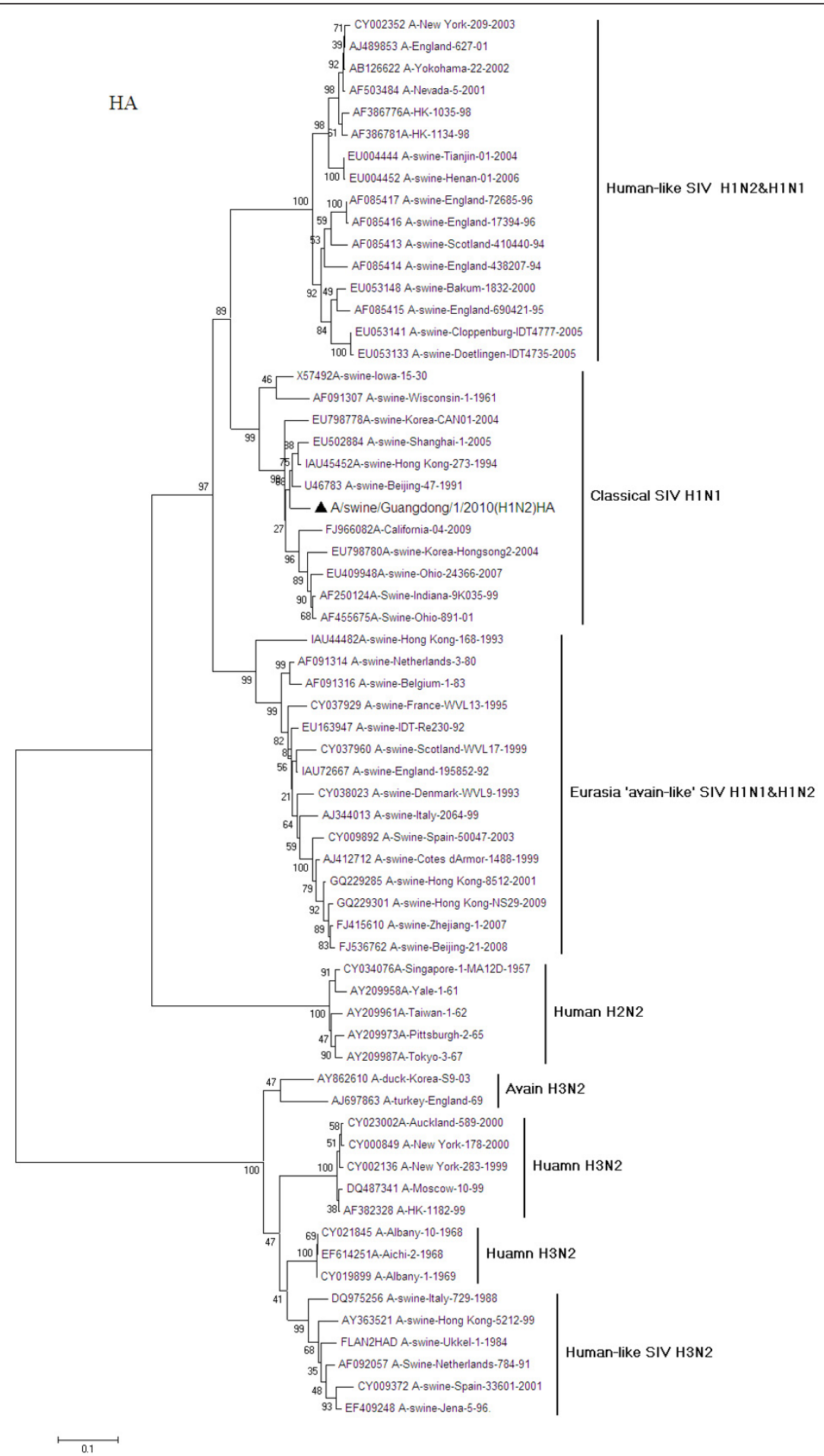

Figure 2 Phylogenetic relationships of the HA gene of A/swine/Guangdong/1/2010 (H1N2) compared to genetically related influenza viruses. Horizontal distances are proportional to the minimum number of nucleotide differences required to join nodes and sequences. Vertical distances are for spacing branches and labels. The phylogenetic trees were generated by using the neighbor-joining alogrithm. The percentage of replicate trees in which the associated taxa clustered together in the bootstrap test (1000 replicates) is shown next to the branches. 


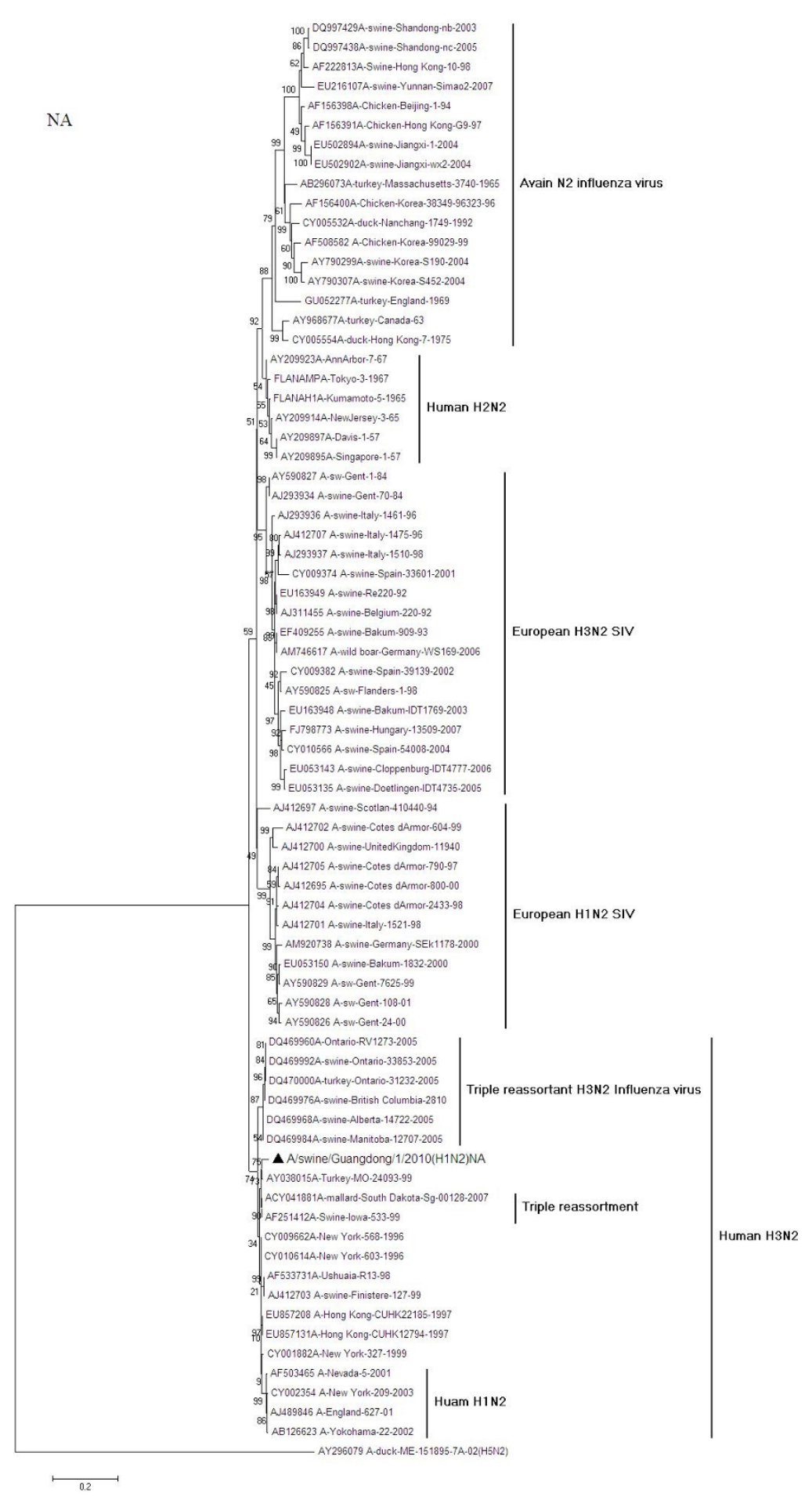

Figure 3 Phylogenetic relationships of the NA gene of A/swine/Guangdong/1/2010 (H1N2) compared to genetically related influenza viruses. Horizontal distances are proportional to the minimum number of nucleotide differences required to join nodes and sequences. Vertical distances are for spacing branches and labels. The phylogenetic trees were generated by using the neighbor-joining alogrithm. The percentage of replicate trees in which the associated taxa clustered together in the bootstrap test (1000 replicates) is shown next to the branches. 
gene, contains various lengths, amino acid sequences, cellular localizations and functions, which in terms displays strain-specific pathogenicity. The PB1-F2 of A/swine/Guangdong/1/2010 expressed a truncated protein including 57 amino acid like most human H1N1 viruses, which has a low homology with A/New York/ $568 / 1996$ and other triple reassortment influenza virus (86.2\%). It is different from A/Swine/Indiana/9K035/99 which coded full-length PB1-F2. The truncated protein may change the levels of expression and cellular localizations [20]. The NS1 protein of this virus contains 219 amino acid, it loss the PL motifs (PDZ domain ligand, $\mathrm{PL}$ ), which located in 227-230aa. This feature is the same with recent classical SIV H1N1 [21].

In China, classical swine influenza virus has been existing since 1996. In the previous epidemiological study, H3N2 infected pigs in this area. The H1N2 was reported in 2004, which is a human-swine reassortment virus [22]. In this study we find the multiple reassortment viruses, it confirmed the swine as a mixing vessel in transmission. This deserves to be paid attention. Especially swine population was seized with FMD after the SIV infected pigs in this area. The 2009 H1N1 pandemic virus is a swine-origin reassortant: HA, NP and NS from classical swine (North American) lineage; PB2 and PA from avian (North American) lineage; PB1 from human seasonal H3N2; and NA and M from Eurasian swine lineage [23]. Southern China is designated as a putative influenza epicenter [24]. Both 1957 and 1968 pandemic influenza emerged from this area. The precursors of currently still ongoing H5N1 HPAIVs were identified also in Southern China. Recently H6 AIVs have been identified in this area [25]. The current situation, therefore, presents continued risk for further reassortment of swine influenza virus in pig populations and continuous monitoring of this virus in swine population will be needed.

\section{Nucleotide sequence accession numbers}

Nucleotide sequences from the A/swine/Guangdong/1/ 2010 (H1N2) isolate have been submitted to GenBank with accession numbers HQ85339 to HQ853346.

\section{Additional file}

Phylogenetic trees for H1N2 swine influenza virus isolated from southern China: (1) PB2; (2) PB1; (3) PA; (4) NP; (5) MP; and (6) NS

\section{Additional material}

Additional file 1: Phylogenetic relationships of the PB2 gene of A/swine/Guangdong/1/2010 (H1N2) compared to genetically related influenza viruses.
Additional file 2: Phylogenetic relationships of the PB1 gene of A/swine/Guangdong/1/2010 (H1N2) compared to genetically related influenza viruses.

Additional file 3: Phylogenetic relationships of the PA gene of A/swine/Guangdong/1/2010 (H1N2) compared to genetically related influenza viruses.

Additional file 4: Phylogenetic relationships of the NP gene of A/swine/Guangdong/1/2010 (H1N2) compared to genetically related influenza viruses.

Additional file 5: Phylogenetic relationships of the MP gene of A/swine/Guangdong/1/2010 (H1N2) compared to genetically related influenza viruses.

Additional file 6: Phylogenetic relationships of the NS gene of A/swine/Guangdong/1/2010 (H1N2) compared to genetically related influenza viruses.

\section{Acknowledgements}

This study was supported by the National Basic Research Program (973 Project) from China Ministry of Science and Technology (Grant No. 2011CB504703-1) and International Cooperative Projects (Grant No. S2011ZR0429) and China Guangdong hundred thousand engineering.

\section{Authors' contributions}

WLK carried out PCR and sequencing reactions and optimized protocols and performed sequence analyses, alignments, phylogenies, interpretation of data, carried out identification of viruses and wrote the manuscript. NC and HTQ revised the manuscript. LZH obtained the clinical samples, organized sample processing. All authors read and approved the final manuscript.

\section{Competing interests}

The authors declare that they have no competing interests.

Received: 11 January 2011 Accepted: 13 October 2011

Published: 13 October 2011

\section{References}

1. Kong Wei-li, Huang Yu-mao, Cao Nan, Qi Hai-tao, Huang Liang-zong, Zhao Meng-meng, Guan Shang-song, Wang Wen-hua, Zhao Fu-rong, Qi Wen-bao, Jiao Pei-rong, Zhang Gui-hong: Isolation and Phylogenetic Analysis of H1N1 Swine Influenza Virus from Sick Pigs in Southern China. Indian J Virol 2011, 22(1):66-71.

2. Brown IH, Hill ML, Harris PA, Alexander DJ, McCauley JW: Genetic characterisation of an influenza A virus of unusual subtype (H1N7) isolated from pigs in England. Arch Virol 1997, 142:1045-1050.

3. Shin Jin-Young, Song Min-Suk, Lee Eun Ho, Lee Young-Min, Kim Seok-Yong, Kim Hyong Kyu, Choi Joong-Kook, Kim Chul-Joong, Webby JRichard, Choi Young-Ki: Isolation and characterization of novel H3N1 swine influenza viruses from pigs with respiratory diseases in Korea. J Clin Microbiol 2006, 44(11):3923-7.

4. Karasin IAlexander, Brown Hlan, Carman Suzanne, Olsen WChristopher: Isolation and characterization of H4N6 avian influenza viruses from pigs with pneumonia in Canada. J Virol 2000, 74:9322-9327.

5. Nidom CA, Takano R, Yamada S, Sakai-Tagawa Y, Daulay S, Aswadi D, Suzuki T, Suzuki Y, Shinya K, Iwatsuki-Horimoto K, Muramoto Y, Kawaoka Y: Influenza A (H5N1) viruses from pigs, Indonesia. Emerg Infect Dis 2010, 16(10):1515-23.

6. Lee JH, Pascua PN, Song MS, Baek YH, Kim CJ, Choi HW, Sung MH, Webby RJ, Webster RG, Poo H, Choi YK: Isolation and genetic characterization of H5N2 influenza viruses from pigs in Korea. J Virol 2009, 83:4205-15.

7. Zhang G, Kong W, Qi W, Long LP, Cao Z, Huang L, Qi H, Cao N, Wang W, Zhao F, Ning Z, Liao M, Wan XF: Identification of an H6N6 swine influenza virus in southern China. Infect Genet Evol 2011, 11(5):1174-7.

8. Sugimura $T$, Yonemochi H, Ogawa K, Tanaka Y, Kumagai T: Isolation of a recombinant influenza virus (Hsw1N2) from swine in Japan. Arch Virol 1980, 66:271-274. 
9. Ito $T$, Vines $A$, Ishikawa $H$, Asai $T$, Kida $H$ : Continued circulation of reassortment H1N2 influenza viruses in pigs in Japan. Arch Virol 1998, 143:1773-1782.

10. Gourreau JM, Kaiser C, Valette M, Douglas AR, Labie J, Aymard M: Isolation of two H1N2 influenza viruses from swine in France. Arch Virol 1994, 135:365-382.

11. Brown IH, Chakraverty P, Harris PA, Alexander DJ: Disease outbreaks in pigs in Great Britain due to an influenza A virus of H1N2 subtype. Vet Rec 1995, 136:328-329.

12. Karasin Al, Anderson GA, Olsen CW: Genetic Characterization of an H1N2 influenza virus isolated from a pig in Indiana. J Clin Microbiol 2000, 38:2453-2456

13. Schrader Christina, Süss Jochen: Genetic Characterization of a Porcine H1N2 Influenza Virus Strain Isolated in Germany. Intervirology 2003, 46:66-70.

14. Jung $\mathrm{K}$, Chae C: Phylogenetic analysis of an H1N2 influenza A virus isolated from a pig in Korea. Arch Virol 2004, 149:1415-1422.

15. Bálint Ádám, Metreveli Giorgi, Widén Frederik, Zohari Siamak, Berg Mikael, Isaksson Mats, Renström HMLena, Wallgren Per, Belák Sándor, Segall Thomas, Kiss István: The first Swedish H1N2 swine influenza virus isolate represents an uncommon reassortant. Virology Journal 2009, 28;6:180.

16. Paton JDavid, King PDonald, Knowles JNick, Hammond Jef: FOOT-ANDMOUTH DISEASE: Recent spread of foot-and-mouth disease in the Far East. Veterinary Record 2010, 166:569-570.

17. Olsen CW, Karasin Al, Carman S, Li Y, Bastien N, Ojkic D, Alves D, Charbonneau G, Henning BM, Low DE, Burton L, Broukhanski G: Triple reassortant $\mathrm{H} 3 \mathrm{~N} 2$ influenza $A$ viruses, Canada, 2005. Emerg Infect Dis 2006, 12(7):1132-5.

18. Ramakrishnan AMuthannan, Wang Ping, Abin Martha, Yang My, Goyal MSagar, Gramer RMarie, Redig Patrick, Fuhrman WMonte, Sreevatsan Srinand: Triple Reassortant Swine Influenza A (H3N2) Virus in Waterfowl. Emerg Infect Dis 2010, 16(4):728-30.

19. Suarez DL, Woolcock PR, Bermudez AJ, Senne DA: Isolation from turkey breeder hens of a reassortant H1N2 influenza virus with swine, human, and avian lineage genes. Avian Dis 2002, 46(1):111-121.

20. Chen $\mathrm{CJ}$, Chen GW, Wang CH, Huang CH, Wang YC, Shih SR: Differential localization and function of PB1-F2 derived from different strains of influenza A virus. J Virol 2010, 84(19):10051-62.

21. Qi X, Lu CP: Genetic characterization of H1N1 swine influenza A viruses isolated in eastern China. Virus Genes 2009, 39:193-199.

22. Qi X, Lu PC: Genetic characterization of novel reassortant H1N2 influenza A viruses isolated from pigs in southeastern China. Arch Virol 2006, 151:2289-2299.

23. Dawood FS, Jain S, Finelli L, Shaw MW, Lindstrom S, Garten RJ, Gubareva LV, Xu X, Bridges CB, Uyeki TM: Emergence of a novel swineorigin influenza $A(H 1 N 1)$ virus in humans. N Engl J Med 2009, 360(25):2605-15.

24. Shortridge KF, Stuart-Harris CH: An influenza epicentre? Lancet 1982, 2(8302):812-3

25. Huang K, Bahl J, Fan XH, Vijaykrishna D, Cheung CL, Webby RJ, Webster RG, Chen H, Smith GJ, Peiris JS, Guan Y: Establishment of an H6N2 influenza virus lineage in domestic ducks in southern China. J Virol 2010, 84(14):6978-86.

\section{Submit your next manuscript to BioMed Central and take full advantage of:}

- Convenient online submission

- Thorough peer review

- No space constraints or color figure charges

- Immediate publication on acceptance

- Inclusion in PubMed, CAS, Scopus and Google Scholar

- Research which is freely available for redistribution

Submit your manuscript at www.biomedcentral.com/submit
Biomed Central 